\title{
A organização do território urbano a partir da relação porto-cidade e seu reflexo na forma urbana
}

\author{
The organization of urban territory from the port-city relationship and its \\ reflection on urban form
}

Rafael Rossetto Ribeiro[a] (D), Gislaine Elizete Beloto[b] (D)

[a] Universidade Estadual de Maringá (UEM), Maringá, PR, Brasil

[b] Departamento de Arquitetura e Urbanismo, Universidade Estadual de Maringá (UEM), Maringá, PR, Brasil

Como citar: Ribeiro, R. R., \& Beloto, G. E. (2020). A organização do território urbano a partir da relação porto-cidade e seu reflexo na forma urbana. urbe. Revista Brasileira de Gestão Urbana, 12, e20190267. https://doi.org/10.1590/21753369.012.e20190267

\section{Resumo}

Do ponto de vista funcional, porto e cidade constituem um conjunto cujas interações e complementariedades variam no tempo sob influência das dinâmicas econômicas, produtivas, tecnológicas e sociais. Considerando essa gama de variáveis, modelos analíticos apontam para a ocorrência de fases comuns e recorrentes em todas as cidades portuárias. Dentro desse cenário, o presente trabalho objetiva demonstrar como as mutações nas relações funcionais entre a cidade e a atividade portuária influenciaram na configuração urbano-territorial. Dublin, capital da República da Irlanda, é o estudo de caso apresentado neste artigo por meio da leitura de sua forma urbana ao longo de uma linha temporal. Neste estudo, o porto é tido como o equipamento-chave das mudanças ocorridas na forma da cidade por associar-se diretamente às alterações no processo produtivo e econômico em escala local e mundial. Ao estabelecer o paralelo entre a atividade portuária e a forma urbana, conclui-se que os diferentes estágios de aproximação e principalmente de afastamento entre a cidade e a atividade portuária criaram centralidades, dispersões e obsolescências no tecido urbano, corroborando na formação de novas organizações territoriais.

Palavras-chave: Forma urbana. Modelo de expansão urbana. Cidade portuária. Modelo conceitual. Dublin.

\section{Abstract}

From a functional point of view, port and city create a set of interactions and complementarities change over time under the influence of economic, productive, technological and social dynamics. Considering these variables, analytical models point to the occurrence of common and recurring phases in port cities around the world. From this standpoint, the present study seeks to reveal how the mutations in the functional relations between the city and the port activity, in conjunction with the productive arrangements, influenced the urban-territorial configuration. For this, a reading of the urban form of Dublin, capital of Ireland, was performed, regarding the design of its occupation over the territory along

RRR é arquiteto e urbanista, mestrando em Arquitetura e Urbanismo, e-mail: rafaelrossetto.arq.urb@gmail.com

GEB é arquiteta e urbanista, doutora em Arquitetura e Urbanismo, e-mail: gebeloto@uem.br 
a time line. In this study, the port is considered to be key equipment for changes in the shape of the city because it is directly associated with changes in the local and global productive and economic process. When establishing a parallel between the port activity and the urban form, it was concluded that the different stages of approach and mainly the distance between the city and the port activity created centralities, dispersion and obsolescence in the urban fabric, corroborating the formation of new territorial organizations.

Keywords: Urban form. Model of urban expansion. Port city. Conceptual model. Dublin

\section{Introdução}

As cidades portuárias se caracterizam por abrigarem uma estrutura que, ao mesmo tempo em que atende funcionalmente a rede mundial de fluxos de mercadorias, faz parte da formação e da forma propriamente dita dos núcleos urbanos em que se inserem. Do ponto de vista funcional, porto e cidade constituem um conjunto cujas interações e complementaridades variam no tempo sob influência das dinâmicas econômicas, produtivas, tecnológicas e sociais. Assim, cidade e porto vivem uma relação complexa, simbiótica e de interdependência. Nesse sentido, as cidades portuárias são tratadas na literatura através de uma análise que parte da inter-relação entre porto-cidade, e não como peças isoladas.

O conceito interface porto-cidade (port-urban interface) é introduzido pelo geógrafo israelita Yehuda Hayuth (1982) para definir uma zona de transição entre as porções territoriais de uso urbano com as de uso portuário. Para Hoyle (1989), as interações nesta interface se dão, muitas vezes, de forma cooperativa e harmônica, podendo, todavia, estabelecerem-se de modo hostil e discordante. Assim, a relação entre porto e cidade é marcada por momentos de aproximações e de fraturas, pois sob os efeitos da globalização e dos rápidos avanços tecnológicos, tanto as cidades quantos os portos se transformaram e, consequentemente, suas interações mudaram de natureza (Boubacha, 1997).

Dentro desse panorama urbano-portuário diversos são os estudos que trataram sobre as transformações na relação porto-cidade (Bird, 1963; Hayuth, 1982; Hoyle, 1989; Meyer, 1999; Ducruet, 2004; Notteboom \& Rodrigue, 2005; Hein, 2011). Menos explorada é a perspectiva de como essas mutações funcionais da atividade portuária influenciaram na transformação do território urbano ao longo do tempo e engendraram a forma das cidades em que se inserem.

Nesse contexto, o artigo parte da premissa que um terminal portuário e suas estruturas complementares - classificadas como estruturas urbano-regionais por, funcionalmente, atenderem a um território de abrangência regional, nacional ou até mesmo internacional - corroboram na formação e/ou da forma propriamente dita da cidade em que se inserem. Ou seja, a presença de tais equipamentos impacta no tecido urbano sob os aspectos morfológicos, tais como o uso do solo, o modo de ocupação e as dimensões dos lotes urbanos. Ao mesmo tempo, em uma escala mais ampla, repercutem na forma urbana, constituindo limites, barreiras e atuando como estruturas condicionadoras de suas dinâmicas de expansão (Panerai, 2006; Solà-Morales i Rubió, 1997).

Com o objetivo de demonstrar as transformações nas relações funcionais entre a cidade e a atividade portuária diante da questão de "como tais mutações influenciaram na configuração urbano-territorial?", e tendo como background a variação dos arranjos produtivos ao longo do tempo, este artigo apresenta um estudo de caso como método de pesquisa, cujo objeto de análise é Dublin, capital da República da Irlanda. Como tática, a pesquisa documental, baseada em fontes secundárias, embasou a leitura desde a gênese urbano-portuária até a cidade portuária contemporânea, assim como a elaboração de diagramas sobre Dublin a ser aqui apresentados. Com resguardo às particularidades locais, a periodização dessa análise remonta aos modelos analíticos da relação porto-cidade.

Para tanto, a análise da evolução da forma urbana de Dublin foi construída com base na formulação de diagramas correlacionando o crescimento da cidade com as áreas portuárias e com as estruturas de transporte rodoviário e ferroviário. Este mapeamento foi possível através da identificação da forma e das 
estruturas urbanas em cartografias históricas, registros iconográficos e imagens de satélites, como a ferramenta imagens históricas do Google Earth. A partir de então, correlacionaram-se as variáveis da forma urbana - forma compacta, fragmentada e dispersa - com as etapas descritas pelos modelos evolutivos da relação porto-cidade de Bird (1963), Meyer (1999) e Notteboom \& Rodrigue (2005).

Desse modo, o artigo se estrutura em três seções. Primeiramente pela apresentação dos modelos analíticos que tratam da evolução das cidades portuárias, com especial enfoque nos diferentes estágios da relação do porto com a cidade, e da cidade com o porto. Em seguida, apresenta-se um panorama acerca do desenho da forma das cidades. Por fim, correlaciona-se a evolução da atividade portuária com as transformações da forma urbana de Dublin.

\section{A evolução da relação porto-cidade}

Dentre os modelos analíticos acerca da evolução das cidades portuárias, os quais revelam momentos de integração e dissociação entre porto e cidade, o mais reconhecido modelo conceitual é o modelo Anyport, de J. Bird (1963). Organizado a partir de uma perspectiva histórico-morfológica da análise em portos britânicos, este modelo (ver Figura 1) descreve em três etapas as transformações funcionais da atividade portuária e os seus desdobramentos nas cidades em que se inserem: estabelecimento, expansão e especialização.

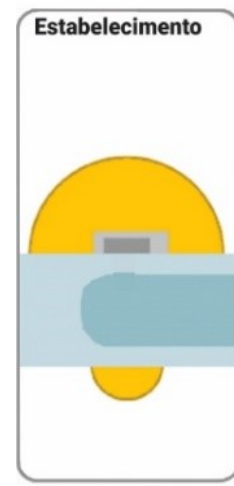

Centro urbano Expansão urbana

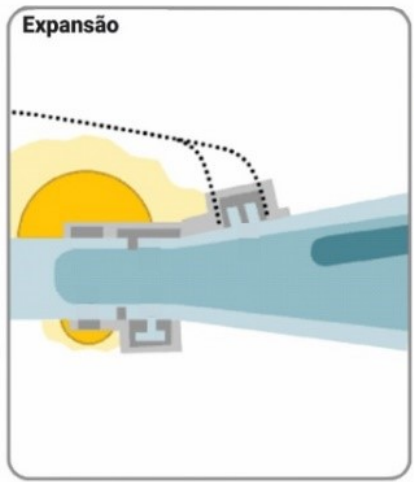

Estruturas portuárias

Atividades portuárias

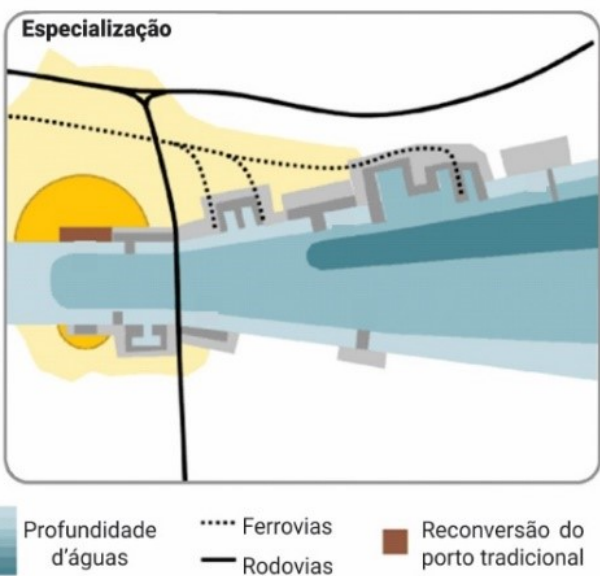

Figura 1 - Modelo Anyport e suas três etapas funcionais e territoriais: estabelecimento, expansão e especialização. Fonte: Bird (1963). Tradução dos autores.

A fase inicial do modelo Anyport refere-se ao estabelecimento (setting), com a implantação do porto sobreposta ao centro urbano. A escolha do sítio urbano-portuário era determinada por questões geográficas, uma vez que as estruturas e o funcionamento do porto primitivo eram rudimentares e estavam vinculados às atividades urbanas centrais, assim como a própria gênese da maioria dessas cidades estava vinculada à implantação desse porto. Na etapa seguinte, a expansão (expansion), tem-se a ampliação das estruturas e da atividade portuária em áreas adjacentes ao porto primitivo. Essa expansão, tanto portuária como também urbana, era decorrente da modernização proveniente dos avanços tecnológicos da era industrial. A terceira e última fase, especialização (specialization), se caracteriza pela intermodalidade e pela efetiva integração das áreas portuárias dentro de cadeias produtivas. Assim, a atividade portuária afasta-se territorialmente da cidade, principalmente dos núcleos centrais originais, rumo às áreas do território que suportassem suas novas funções e integrações. Em certas cidades, esse movimento ocasionou o abandono e degradação físico-social dos antigos núcleos portuários. Em muitos casos, a partir da década de 1980, houve a reconversão dessas frentes marítimas através de projetos urbanos. 
Embora a formulação desse modelo tenha como base as cidades portuárias localizadas no território britânico, suas etapas podem e são verificáveis também em outros territórios - como o próprio nome do modelo analítico indica (Anyport em inglês significa "qualquer porto") -, os quais os portos e as cidades tenham sua origem concomitante. Contudo, apesar do reconhecimento da importância deste modelo generalizável de Bird (1963) nos estudos sobre a evolução das cidades-portuárias, Notteboom \& Rodrigue (2005) apontam para a ausência de aspectos relativos ao desenvolvimento portuário contemporâneo, tais como os hub ports ${ }^{1}$ e as redes de distribuição de mercadorias. Assim, os autores acrescentaram a fase de regionalização portuária (port regionalization) ao modelo Anyport.

De acordo com Notteboom \& Rodrigue (2005), com a regionalização portuária, o funcionamento dos portos dependem da formação de uma rede composta por diferentes plataformas multimodais em um vasto território (ver Figura 2). Dentre os fatores que contribuem para a formação dessa rede, situam as restrições locais e as mudanças globais, tais como: a falta de áreas propícias para a expansão portuária nos antigos centros; a necessidade de águas profundas que supram os avanços do sistema náutico; a sobrecarga dos sistemas rodoferroviários; os problemas ambientais; e principalmente os novos padrões de produção e consumo, para os quais se faz necessário o desenvolvimento de uma rede de distribuição que corresponda à desconcentração desses padrões por um território que não abrange mais somente a cidade, mas sim uma região, e às vezes até mesmo um país.

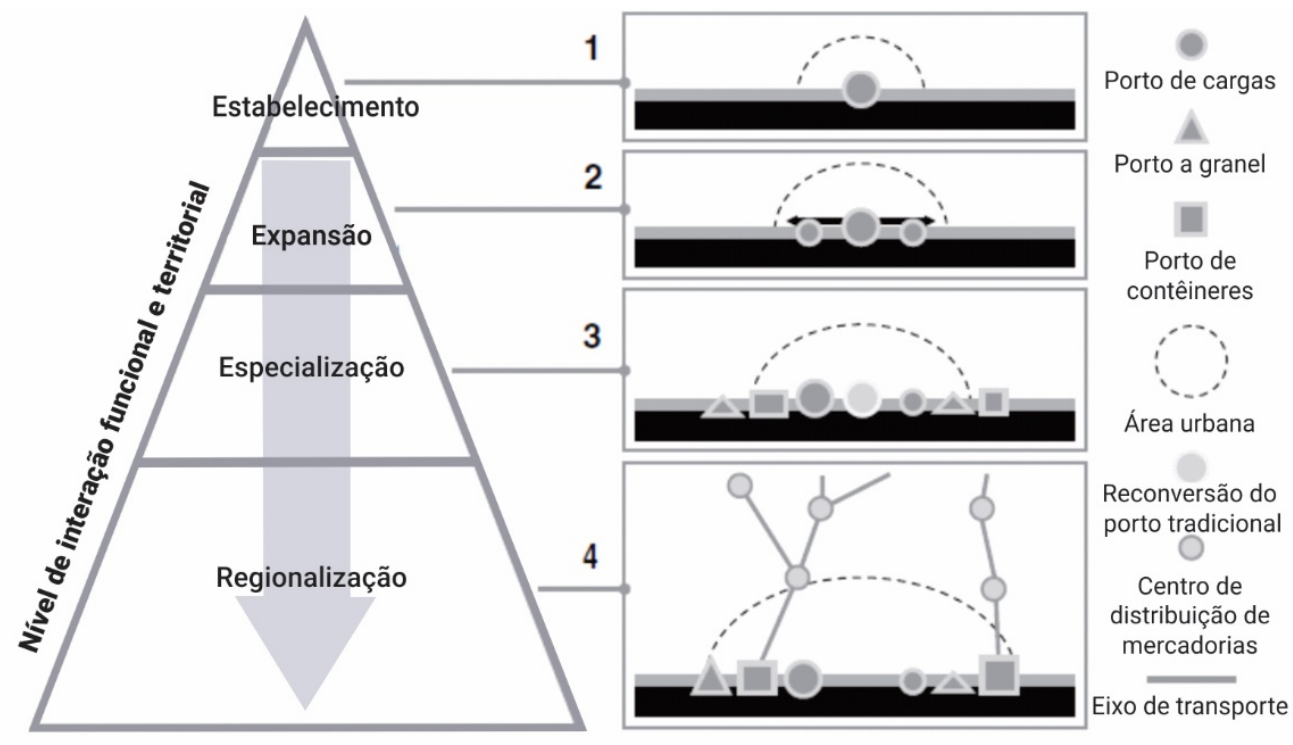

Figura 2 - A evolução da cidade portuária. Fonte: Notteboom \& Rodrigue (2005). Tradução dos autores.

De modo similar a estes modelos apresentados, o holandês Han Meyer (1999) identificou quatro estágios inter-relacionando a atividade portuária com o território urbano (ver Figura 3). Entretanto, Meyer destaca a influência dos ciclos da economia capitalista na determinação de cada um desses estágios evolucionários das cidades portuárias. Para tanto, aproxima-se das bases teóricas do economista russo Nikolai Kondratiev, autor da Teoria das Ondas Longas. De acordo com Kondratiev, a dinâmica capitalista não é linear. Apresenta-se em ciclos que consistem na alternância de períodos com alto crescimento econômico e de períodos de recessão. Em geral, o ponto de virada para um novo ciclo é causado pela introdução de uma nova tecnologia ou um novo modelo produtivo.

Por exemplo, a cidade portuária do final do século XVIII até a metade do século XIX funcionava como o ponto final para bens e mercadorias produzidos em seu território de influência, onde eram mantidos

1 Os megaportos (hub ports) são plataformas de concentração e redistribuição de contêineres, configurando-se como nós de uma rede global de fluxos rápidos, multiplicador de lógicas desterritorializadas. Os altos investimentos em portos dessa tipologia resultam em “[...] uma nova geração de portos-indústria inseridos nas cadeias de valor de atores econômicos cujas escalas de ação ignoram o nível local” (Vasconcelos, 2011, p. 10). 
em depósitos, processados e/ou comercializados. Na segunda metade do século XIX, a cidade portuária refletiu a era da mudança na infraestrutura, baseada na ascensão das ferrovias e do aço como elemento construtivo. Distantes do núcleo central das cidades, os portos tornaram-se elos de conexão entre as rotas marítimas e ferroviárias. No que lhe concerne, o século XX trouxe a reconfiguração dos portos em centros de produção industrial e transbordo. Assim, houve autonomia na operação portuária perante os arranjos urbanos. Por fim, a partir da segunda metade do século XX há uma notável desconcentração da atividade portuária e a sua integração com uma rede logística de ampla escala de influência (Meyer, 1999).

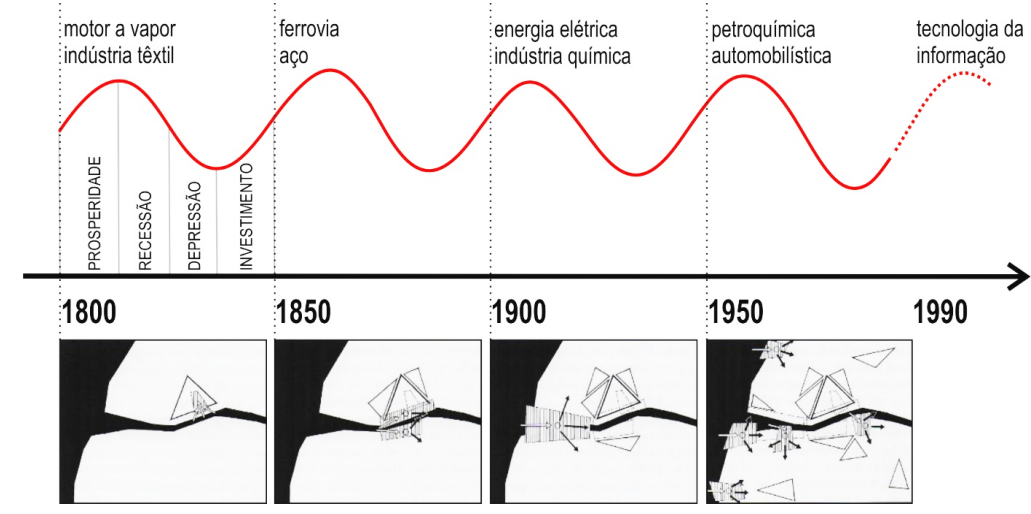

Figura 3 - Tipificação dos estágios na relação porto-cidade e os ciclos econômicos de Kondratiev. Fonte: Meyer (1999). Tradução dos autores.

Portanto, o impacto da desconcentração da área portuária na forma da cidade vai à mesma direção da descentralização do comércio, ou seja, a dispersão da mancha urbana sobre o território. A repercussão tem sido o abandono progressivo das antigas estruturas portuárias, devido à sua obsolescência diante das novas tecnologias e das novas redes de logística. $\mathrm{O}$ final do século XX demonstra a dissociação portocidade, o que não se traduz automaticamente em uma retirada generalizada das funções portuárias para outras porções do território. Em muitos casos, os portos tradicionais inseridos nos centros urbanos ou adjacentes a eles mantêm suas atividades de modo parcial, ou para fins específicos, como o transbordo de pessoas para turismo e lazer. De qualquer forma, o atual arranjo da atividade portuária aliado à informatização do território induz à eliminação de qualquer tipo de limite à expansão e à forma das cidades portuárias.

\section{O desenho da forma urbana}

A forma urbana pode ser entendida como o resultado de um processo em que o ponto de partida não é a própria forma, contudo, em um espectro temporal, as transformações na forma da cidade são tidas como certas. Assim, tal como um palimpsesto, a forma carrega em si marcas dos processos que lhe deram origem. As permanências ficam por conta dos resíduos estruturais da forma. Ambas, as transformações e as permanências, são verificáveis na forma urbana em sua totalidade e na constituição dos tecidos urbanos (Corboz, 2004; Conzen, 2004).

De maneira mais abrangente, a mancha urbana sobre o território pode ter sua forma definida como compacta, fragmentada, dispersa e difusa (Arellano, 2007). A forma urbana compacta é aquela que durante séculos tipificou as cidades e claramente diferenciava-as das áreas rurais. Ou seja, refere-se à forma canônica das cidades: limites bem definidos e dimensões reduzidas. Essa tipificação da cidade compacta vem de sua origem medieval, quando as necessidades defensivas engendravam um núcleo urbano contido pelas suas muralhas e fortificações. Essa formatação definia uma nítida distinção entre o que estava dentro da fortaleza, o burgo, e o que estava fora, o campo.

A forma fragmentada deriva da expansão do tecido urbano pelo território, extrapolando seus limites iniciais e suprimindo as muralhas que originalmente continham as cidades. Esse crescimento extensivo 
das cidades ocorre com o estabelecimento das redes ferroviárias no século XIX e se intensifica, posteriormente, com a implantação da rede de rodovias ao longo do século XX. Assim, ao contrário da forma compacta, a cidade que se expande e se fragmenta pelo território rural começa a perder a clareza de seus limites. Isso dificulta sua percepção, mas não impossibilita o desenho de uma linha de contorno.

A forma dispersa está relacionada às dinâmicas econômicas, as quais incluem a transformação da cidade industrial em uma cidade informacional, ou informational city (Castells, 1989). Em termos morfológicos, a forma dispersa é caracterizada pela descontinuidade das peças urbanas e, sobremaneira, pela perda da clareza de seus limites. As áreas de urbanização dispersas se estendem amplamente pelo território. São separadas territorialmente, mas se mantêm espacialmente vinculadas através de troncos viários. Por meio destes há o deslocamento a partir do centro das atividades econômicas pelo território e a disseminação de modos metropolitanos de habitação, trabalho e lazer. 0 que altera o modo de vida e de consumo dos seus habitantes (Reis, 2006; Arellano, 2007).

Por sua vez, a forma difusa é conceituada pela dissolução da cidade e a extensão dos valores urbanos por um vasto território. Esse modelo territorial advém do termo città diffusa escrito por Indovina (2009), que utilizou tal terminologia para explicar a forma da região de Vêneto, Itália. Nela, a cidade difusa se estende por um amplo território rural formando uma mancha urbana de baixíssima densidade populacional e sem limites definidos.

De acordo com Adams (1970), Van den Berg et al. (1982) e Costa (2007), as formas das cidades estiveram historicamente condicionadas pela maneira em que se obtêm e se armazenam os suprimentos, seja através de uma produção própria e/ou transportando de outras localidades, e pela distância máxima que se vencia para realizar as atividades relativas à vida urbana cotidiana. As mudanças nas condições de mobilidade urbana, produção e consumo ao longo do tempo refletiram em alterações na configuração urbana. Mas não apenas isso. Em se tratando de cidades portuárias, os apontamentos de Zaremba (1962) mostram como as características geográficas são determinantes na dinâmica de expansão dessas cidades, assim como da própria atividade portuária. Segundo o autor, em cidades portuárias situadas na embocadura de um rio com o mar, a área portuária tem sua expansão direcionada a jusante do rio. Em contrapartida, o tecido urbano se expande direcionado pelos eixos de transporte terrestres, em sentido transversal ao da expansão da área portuária. Movimento este que vai levando à gradativa dissociação porto-cidade. No caso de cidades portuárias situadas diretamente na borda do mar, o desenho da forma urbana é condicionado pela linha costeira, acompanhando a estrutura natural. A partir do núcleo urbanoportuário inicial, as expansões do tecido urbano e da área portuária tomam a mesma direção, mas com sentidos opostos, orientados pelos eixos de transporte que, neste caso, correm paralelos ao mar.

De modo geral, o que Zaremba (1962) apresenta com relação às características geográficas, Panerai (2006) demonstra por meio dos elementos reguladores do crescimento urbano. Para este autor, fisicamente, o crescimento das cidades é regulado pela relação entre duas categorias de elementos: aqueles que organizam a expansão urbana e aqueles que contêm a expansão territorial da cidade. Suas origens são tanto naturais - corpos hídricos ou cadeia de montanhas - como também antrópicas - eixos de transportes, portos, aeroportos, shoppings centers e hipermercados. Obviamente que, em cidades portuárias, ambas estruturas - naturais e antrópicas - estão fortemente presentes, sendo as estruturas naturais as primeiras a conterem e moldarem as formas das cidades. 0 conjunto de estruturas antrópicas composto pelo terminal portuário, área retroportuária e eixos rodoferroviários, regula o crescimento urbano, quase sempre organizando-o. Assim, a matriz de expansão da cidade portuária resume-se na associação entre a principal estrutura econômica-natural, ou seja, rio e/ou mar, e as estruturas de conexão terrestre. A elasticidade que os deslocamentos das pessoas e das mercadorias ocorrem por essas estruturas promove estágios de compacidade, fragmentação e dispersão nas formas urbanas em que se inserem. 


\section{Formas e estruturas: a configuração urbano-territorial na cidade de Dublin, Irlanda}

A periodização da leitura a seguir feita sobre Dublin remonta aos modelos analíticos explanados anteriormente acerca das cidades tradicionalmente portuárias. A intrínseca relação da cidade irlandesa com a atividade portuária é reconhecida ao observar os desdobramentos históricos materializados no território urbano. Assim, a narrativa que se segue dirige-se ao passado para entender a relação portocidade na contemporaneidade e demonstrar como a atividade portuária influenciou nos diferentes estágios de organização do território urbano.

\section{Do vilarejo medieval à fragmentada cidade industrial}

Dublin acomoda-se no delta do rio Liffey com o mar da Irlanda e aos pés da cadeia montanhosa de Leinster. Essa situação geográfica oferece fácil acesso tanto ao interior da Ilha, como também ao restante do continente europeu através do ancoradouro natural formado pelos corpos hídricos. Desde o início da sua ocupação pelos vikings no século XII, eram evidentes estas potencialidades de conexão do território que a transformariam em um importante centro urbano, impulsionando seu crescimento econômico e territorial. Assim, a localização da cidadela medieval (ver Figura 4) reflete essa origem, ocorrendo em um ponto elevado próximo à embocadura do rio com o mar, o que propiciava melhor condição de proteção e defesa, enquanto também possibilitava as conexões exteriores.

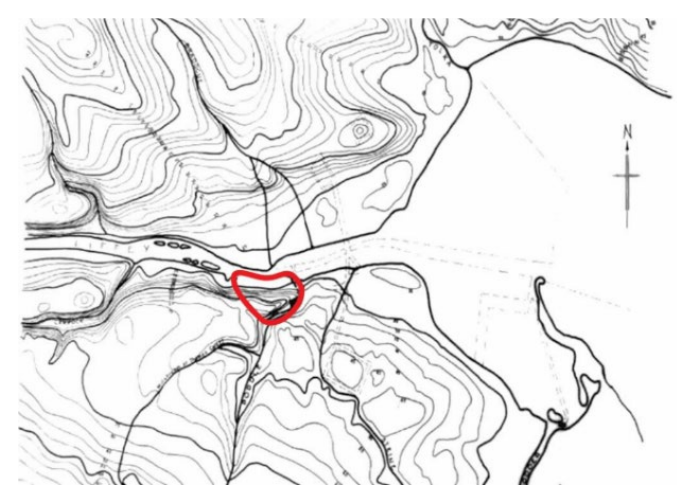

Figura 4 - Localização do assentamento medieval de Dublin, século XII. Fonte: Burkle (1972, p. 31).

No início do século XVII, com a subjugação de toda a Ilha da Irlanda a um governo único e o estabelecimento de Dublin como sua sede político-administrativa, iniciou-se um importante processo de transformação na forma da cidade, com a ocupação urbana para além dos seus limites medievais. Neste período, a matriz econômica da Ilha da Irlanda era a exportação de produtos agrícolas. Logo, o porto de Dublin era o ponto de convergência nacional para comercialização de sua produção. Dessa maneira, a atividade portuária teve importante papel na consolidação da hegemonia de Dublin como uma centralidade dentro do conjunto de cidades irlandesas (Burkle, 1972).

Essa valorização econômica e territorial das cidades portuárias, e identificada em Dublin, baseia-se nas interações funcionais entre as estruturas pertencentes à cidade e a atividade portuária sobre um território de influência e abrangência. Esta é funcionalmente descrita como transbordo, armazenamento e negócios diversos, relacionada ao conjunto de estruturas que dão suporte ao seu funcionamento e aos arranjos produtivos. 0 porto, no que lhe concerne, representa a porção do território onde ocorre a conexão entre o transporte terrestre e o marítimo. Assim, os portos, e por extensão as cidades portuárias, são caracterizados como sinapses, isto é, pontos de conexão dentro de um conjunto e/ou uma rede urbana. As sinapses de uma rede urbana são áreas ativas na organização territorial, onde ocorre a facilitação da passagem de informações e onde se convergem os fluxos de trocas. De tal modo que podem criar centralidades urbanas baseadas nas funções que exercem sobre o território (Ducruet, 2004). 
A amarração da atividade portuária com o território, ou melhor dizendo, a circulação de mercadorias baseada na convergência ao porto, estabeleceu uma estrutura viária que, além do próprio porto, conectava a cidade de Dublin ao território irlandês. Tais estruturas acabaram por tornar-se reguladoras da expansão urbana local (ver Figura 5).

Em sentido oposto ao crescimento da cidade, a área portuária gradativamente se ampliava frente ao mar da Irlanda (ver Figura 5). A ampliação advinha dos avanços tecnológicos ocorridos com a Revolução Industrial a partir da segunda metade do século XVIII e a consequente transformação da cidadela de Dublin em uma cidade industrial. Dessa maneira, a produção primária passou a ser direcionada às fábricas locais e, após a industrialização e adição do valor agregado ao produto, era exportada pela via marítima.

O arranjo produtivo com base na industrialização materializou-se no tecido urbano com a ampliação das áreas de estocagem, a expansão das zonas fabris e na conexão entre as áreas produtivas. A criação dessa cadeia produtiva formada pelo conjunto campo, indústria e porto necessitava de uma maior fluidez nos deslocamentos entre a matéria-prima, o produto industrializado e o mercado consumidor. A solução foi baseada no desenvolvimento do modelo de conexão radioconcêntrico, que divergia a partir de um ponto central - correspondente à imbricação entre o centro urbano e a área portuária - associado a um anel viário (Circular Road, 1763) que margeava a cidade a partir do porto (Burkle, 1972). Portanto, mesmo diante de expansões e a supressão dos limites medievais, a forma da cidade de Dublin (ver Figura 5), no início do século XIX, era fortemente caracterizada pela compacidade do seu tecido urbano e pela clareza de seus limites, demarcado agora pela via circular e não mais pelas suas muralhas iniciais.
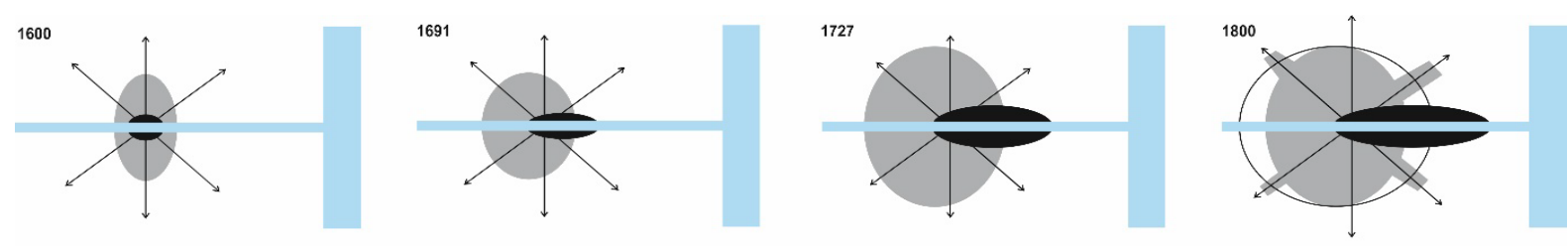

Figura 5 - Diagramas correlacionando a forma urbana de Dublin com a atividade portuária entre os anos 1600 e 1800. Em cinza: mancha urbana; preto: atividades portuárias e industriais; azul: rio Liffey (linha horizontal) e mar da Irlanda (mancha vertical); linha preta: eixos de conexão. Fonte: Elaborado pelo autor com base na cartografia apresentada por Burkle (1972, p. 71, 121, 265, 469).

Em contrapartida, a perda da compacidade da forma urbana de Dublin foi sendo progressiva ao longo do século XIX, à medida que houve maior facilidade no deslocamento das pessoas e das mercadorias pelo território. Os reflexos da implantação das primeiras ferrovias e a formação de novos assentamentos urbanos distantes do núcleo original de Dublin sinalizavam que a forma da mancha urbana, marcada pela sua compacidade, tenderia a mudanças com o passar das décadas. Esse processo resultou tanto na criação de áreas residenciais nas bordas da cidade, como também na instalação de atividades econômicas em outras porções do território que não mais as centrais. Consequentemente, isto refletiu na estrutura organizacional da cidade, que, paulatinamente, vai deixando de ser monocêntrica para se tornar policêntrica. Os fluxos de trocas comerciais que ocorriam em sentido à porção central da cidade superaram os limites do centro tradicional. $O$ avanço da ocupação urbana pelo território rural condicionado pelas vias de transporte e a rapidez com que se vencia as distâncias mais longínquas em comutações diárias propiciaram a implantação e desenvolvimento de assentamentos residenciais descontínuos ao núcleo urbano compacto e central (ver Figura 6) (Horner, 1979). 

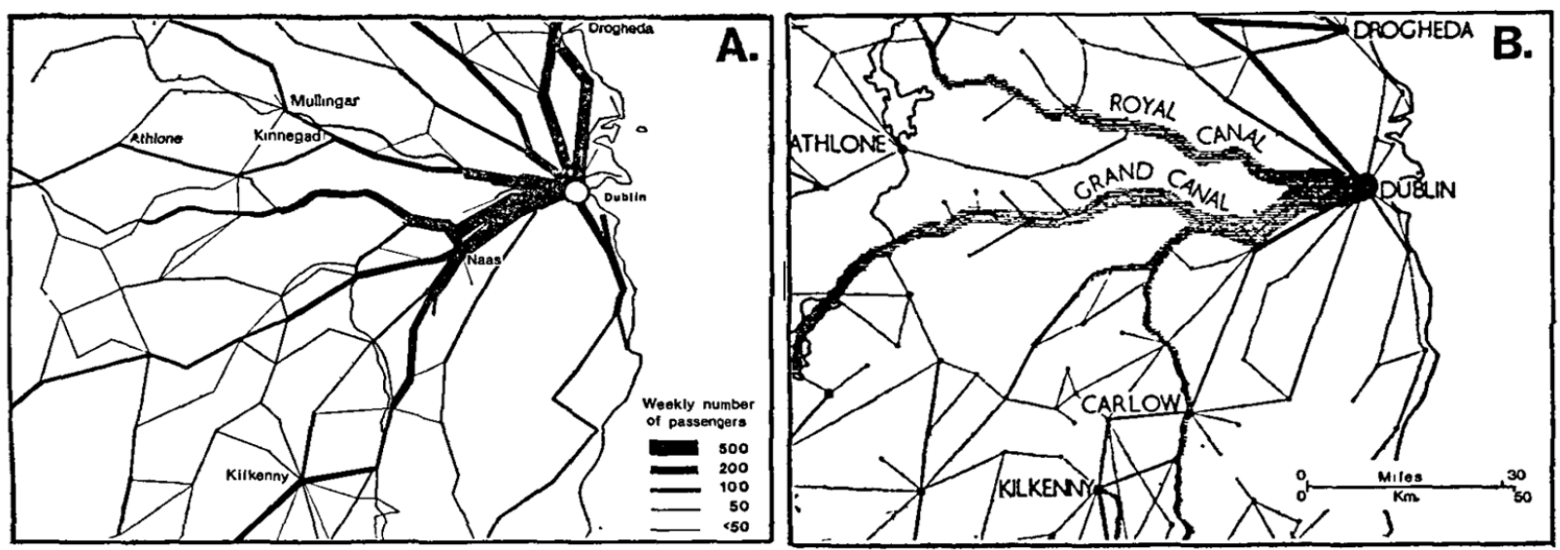

Figura 6 - Padrões de movimentações de passageiros (A) e de mercadorias (B) em 1837. Fonte: Horner (1979, p. 83).

Essa desconcentração pode ser exemplificada com a implantação do seu primeiro trecho ferroviário em 1836, que interligava a área central de Dublin ao vilarejo de Kingstown na porção sul da cidade (ver Figura 7). 0 trajeto ferroviário de 10 quilômetros tinha o objetivo de conectar as docas portuárias centrais no rio Liffey com o novo píer criado no subúrbio. Como repercussão, houve o crescimento econômico e territorial do então vilarejo residencial, sendo inserido na rede urbana de Dublin como um centro de relevância secundária.

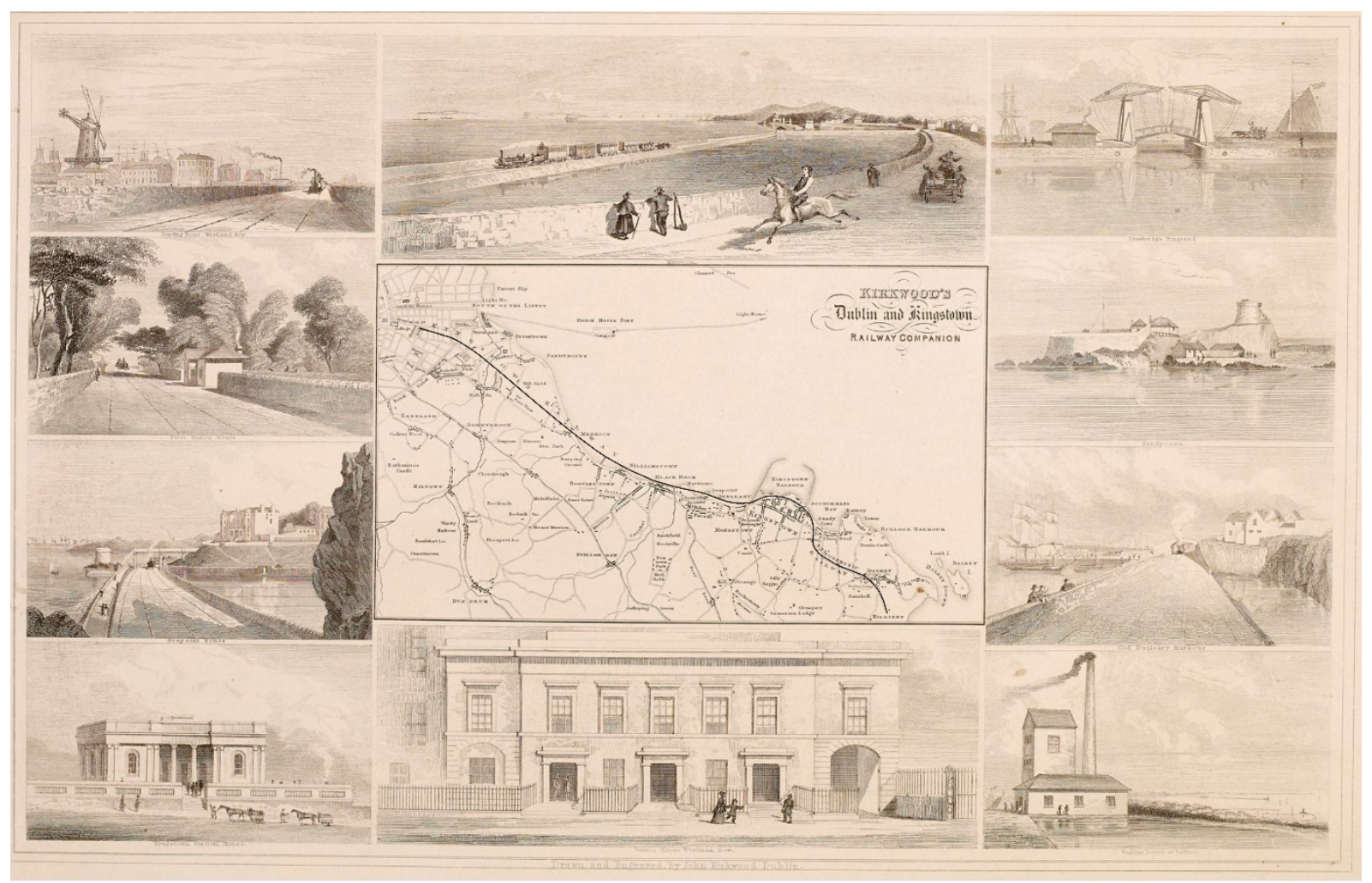

Figura 7 - Mapeamento da primeira ferrovia no território irlandês, interligando o porto central de Dublin com o píer e subúrbio de Kingstown, e perspectivas da paisagem periurbana que se formava (1836). Fonte: acervo da National Library of Ireland.

Na escala territorial, a marca da fragmentação da mancha de Dublin ocorreu nas primeiras décadas do século XX (ver Figura 8). 0 aumento generalizado dos assentamentos residenciais distantes do núcleo tradicional e a crescente conexão de Dublin em uma rede urbana resultaram na perda de clareza do limite 
da cidade. Afinal, esta não era mais uma cidade compacta, e os fragmentos que passam a configurá-la começaram a dificultar o estabelecimento preciso dos limites da sua forma urbana.

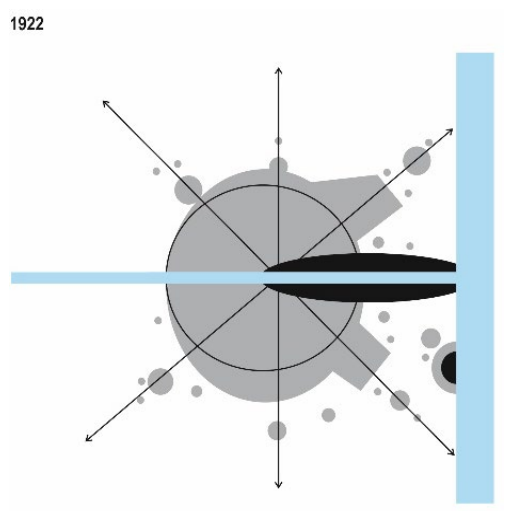

Figura 8 - Diagrama correlacionando a forma urbana de Dublin com a atividade portuária em 1922. Em cinza: mancha urbana; preto: atividades portuárias e industriais; azul: rio Liffey (linha horizontal) e mar da Irlanda (mancha vertical); linha preta: eixos de conexão. Fonte: Elaborado pelo autor com base na cartografia apresentada por Horner (1979, p. 83).

\section{A dispersão urbana planejada}

No início do século XX, a alta densidade populacional da área central da cidade de Dublin era uma eficaz justificativa para potencializar o seu crescimento urbano extensivo. Os índices chegaram a 17 pessoas por habitação (MacLaran, 1993). Com isso, ocasionada pelo crescimento econômico atrelado a um rápido crescimento populacional desde a independência irlandesa em 1916, havia a demanda pela ampliação da sua fronteira urbana.

Não diferente do que vinha ocorrendo em outras cidades ocidentais, a região também passou a ser a escala do planejamento territorial de Dublin nas décadas subsequentes à Segunda Guerra Mundial. Pautada pelo desenvolvimento econômico, a região tornou-se o suporte físico e estratégico para implementar as teorias econômicas (Beloto, 2015, 2019). The Dublin Region: Advisory Regional Plan \& Final Report, elaborado pelo britânico Myles Wright e publicado em 1967, explanava o panorama da cidade e região de Dublin e apresentava diretrizes estratégicas a serem aplicadas pelos seus gestores locais para atingir um crescimento ordenado da cidade-região (MacLaran \& Punch, 2004).

O objetivo do plano de Wright era equilibrar a dinâmica econômica e urbana e facilitar as conexões entre as diferentes partes da região. A configuração urbano-territorial proposta por Wright para Dublin se respaldava no ideário britânico de organização territorial vigente na época: a descentralização planejada; a limitação do tamanho da cidade; o acesso equilibrado a equipamentos, tais como parques e escolas; a relação urbano-rural; e a organização da cidade em unidades de vizinhanças (Howard, 1902; Abercrombie, 1943; Purdom, 1949). Dessa maneira, as diretrizes apresentadas no plano de Wright para Dublin focavam: (1) na descentralização das atividades secundárias e terciárias; (2) na conexão das atividades econômicas e urbanas através de uma grelha de vias de transporte rápido, ao contrário do sistema radial vigente na malha urbana de Dublin; (3) no direcionamento da expansão urbana a oeste; (4) na criação de quatro novas cidades lineares separadas entre si por faixas de áreas livres; e (5) na autossuficiência dos novos núcleos urbanos em geração de emprego e na oferta de comércios e serviços, diminuindo a dependência dos subúrbios pela área central e minimizando a congestão das vias urbanas (ver Figura 9). 


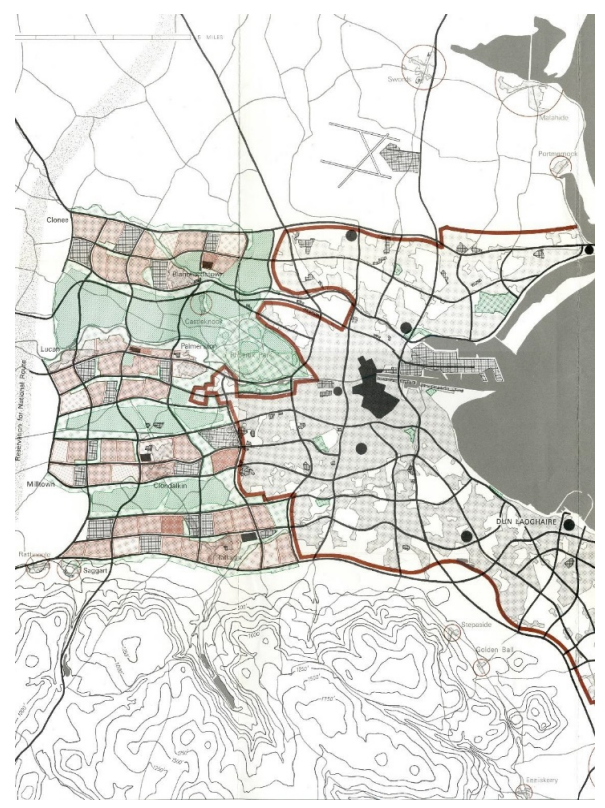

Figura 9 - Plano de Wright para Dublin (1967). Mancha preta: núcleo central; mancha cinza: área residencial existente; pontos pretos: novos centros secundários; mancha preta quadriculada: áreas industrial e portuária; mancha vermelha: nova frente de expansão das áreas residenciais; mancha verde: espaços livres. Fonte: The

Dublin Region: Advisory Regional Plan \& Final Report (1967) apud MacLaran \& Punch (2004).

A proposta de Myles Wright para Dublin não foi formalmente implementada, contudo, a essência de seu trabalho permaneceu no ideário do planejamento urbano-regional irlandês. Especialmente após a entrada da República da Irlanda na Comunidade Econômica Europeia em 1973, a proposta de criação de núcleos urbanos autossuficientes a oeste da cidade de Dublin foi retomada. Neste momento, devido à dimensão territorial que a ocupação urbana assumia, juntava-se ao mar no sentido leste, as montanhas de Leinster ao sul e o aeroporto ao norte como limites à expansão da cidade. Dessa maneira, a direção oeste oferecia o território adequado para o crescimento territorial da cidade e a implantação desses novos núcleos (new towns), conforme previsto por Wright. 0 plano para Tallaght, a sudoeste da cidade existente, exemplifica tais objetivos. Ele foi elaborado com base nas conexões rodoviárias, na diversidade de usos do solo e na provisão de amplos espaços livres (ver Figura 10) (MacLaran \& Punch, 2004).

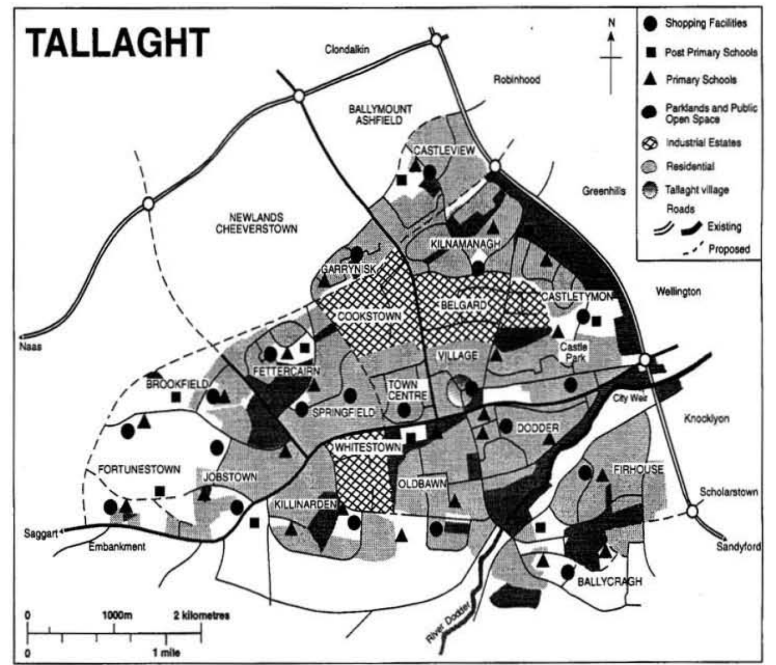

Figura 10 - Plano para criação e desenvolvimento de novo núcleo urbano - Tallaght (1972). Círculo: comércio e serviço; quadrado e triângulo: edifícios institucionais; mancha preta: parques e espaços livres; mancha quadriculada: área de escritórios e indústrias; mancha cinza: área residencial. Fonte: MacLaran \& Punch (2004, p. 26). 
Nos países centrais, a partir da década de 1970 e no decorrer das décadas subsequentes, marca-se a saturação do modelo econômico vigente, exigindo novas formas de regulação do mercado de trabalho e de produção, conduzindo, a partir de então, o fordismo a um processo de decadência que perdurou décadas, mas que foi acentuado com a ascensão do modelo de produção toyotista ou pós-fordista. A necessidade premente era a expansão do mercado consumidor, assim como a queda nos custos de produção. Assim, políticas de liberalização da economia, da flexibilização na produção e de desregulamentações faziam parte da nova agenda econômica destes países. Neste momento, alguns dos avanços tecnológicos que já haviam ocorrido tiveram seu uso difundido e aprimorado. É o caso dos contêineres e dos grandes navios desenvolvidos a priori para fins militares na Segunda Guerra Mundial, mas que passaram a atender ao transporte de cargas em escala de exportação. Esta revolução na tecnologia logística suportou a expansão exponencial do comércio internacional e o espraiamento da produção pelo território, que não tinha mais a localização, principalmente centralizada, como fator determinante para sua instalação e funcionamento (Castells, 1989).

Em Dublin, a instalação de atividades secundárias e terciárias nas bordas da cidade, como o exemplo de Tallaght, acelerou a dispersão urbana na capital irlandesa. Essa nova configuração urbano-territorial de Dublin ocorreu principalmente pela formação de uma rede logística de abrangência regional, nacional e internacional, com a instalação de estruturas complementares à atividade portuária aliadas ao estabelecimento de atividades secundárias e terciárias nas cidades de borda da mancha urbana, ou edge cities, como descreve Joel Garreau (1991). Assim, novos centros secundários autônomos ao centro tradicional foram implantados ao longo dos eixos de transporte, e cada vez mais distantes espacialmente do centro tradicional (ver Figura 11). Por outro lado, a transferência de funções urbanas para outras centralidades, antes encontradas somente no centro tradicional, resultou na obsolescência das históricas estruturas portuárias centrais (Bertz, 2002; MacLaran \& Punch, 2004; Redmond et al., 2007).

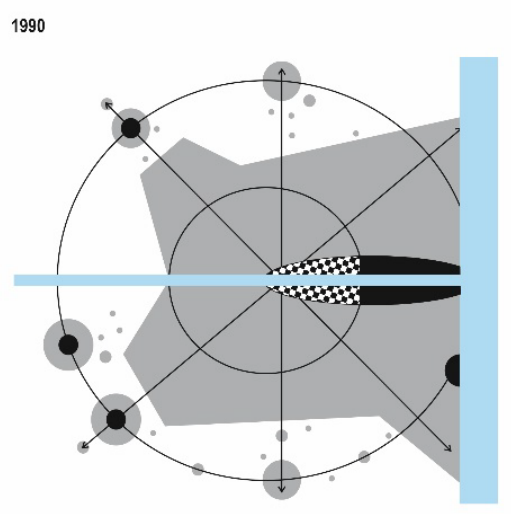

Figura 11 - Diagrama correlacionando a forma urbana de Dublin com a atividade portuária em 1990. Em cinza: mancha urbana; preto: atividades portuárias e industriais; azul: rio Liffey (linha horizontal) e mar da Irlanda (mancha vertical); quadriculado em preto e branco: porção central obsoleta; linha preta: eixos de conexão. Fonte: Elaborado pelo autor com base nas imagens de satélite Google Earth (Google, 2019).

\section{Centralidades e o Centro de Dublin na contemporaneidade}

A partir da década de 1980, o discurso referente à descentralização e ao abandono dos centros tradicionais cede lugar para a (re)valorização cultural, econômica e espacial de tais áreas através de projetos urbanos de renovação e remodelação, que acabam tornando-se áreas estratégicas dentro da competitividade entre as grandes cidades, principalmente no continente europeu (Tourinho, 2007). Dentro desse panorama, as tradicionais áreas portuárias tornam-se o palco para essas ações de renovação devido à obsolescência ocasionada pelos arranjos produtivos descentralizadores vivenciados ao longo do século XX. 
Com o objetivo de alcançar a (re)consolidação da centralidade principal de Dublin, o seu porto tradicional foi objeto de proposta intervencionista em 1986, através do Urban Renewal Act, estabelecendo uma parceria público-privada para a gestão do antigo espaço portuário. Contudo, foi somente a partir de 1996 que significativas alterações físicas foram realizadas e que consequentemente repercutiram em sua dinâmica urbana. Cabe entender que, embora abrangendo a área portuária, o referido projeto urbano desconsidera a sua funcionalidade original - porto e indústria - e incorpora a então recente organização produtiva do território baseada no setor terciário e na indústria enxuta (Moore-Cherry \& Vinci, 2012).

A renovação da frente marítima e a efetiva desvinculação da atividade portuária com a área central consolidou a difusão das atividades portuárias e produtivas pelo território. As estruturas portuárias inicialmente concentradas no seu centro tradicional se instalaram, em um primeiro momento, nas bordas da cidade, para gradativamente se apropriarem do território regional. Assim, a força de aglomeração e suas vantagens resultantes da concentração de capital e população, que compactou a forma da cidade portuária em sua origem, foram diminuídas pelo crescimento das suas desvantagens e pela percepção de que seus benefícios poderiam também ser alcançados em outras porções do território. É precisamente essa mudança no sistema produtivo e logístico que provocou outra configuração ao território urbano (Hall \& Pain, 2006).

A descentralização das atividades portuárias e produtivas resultou na formação de uma rede urbanoregional (ver Figura 12). Em termos genéricos, a rede urbano-regional constitui-se pelo conjunto de centros urbanos funcionalmente articulados entre si. É, portanto, um caso particular de rede na qual os seus nós são os diferentes núcleos dotados de funções urbanas, e as ligações são os diversos fluxos entre esses centros (Corrêa, 2003). Essa organização territorial de Dublin e região, denominada de Grande Dublin (Greater Dublin), atualmente incorpora $40 \%$ da população e também da economia nacional, e assim repercute na dispersão da cidade e na efetiva extensão dos valores urbanos por um vasto território (Hall \& Pain, 2006).

Portanto, enquanto desenho de sua mancha urbana, a porção central de Dublin e os núcleos de borda passam por um crescimento extensivo, que em muitos casos causa o seu efetivo entrelaçamento, e gera certa compacidade à sua forma. Contudo, novos fragmentos são criados através de: (1) assentamentos urbanos em áreas rurais e (2) da implantação de unidades portuárias-industriais em outras porções do território, cada vez mais distantes do núcleo central. Esses novos fragmentos de ocupação urbana e a constituição desta uma rede urbano-regional, que atinge até 90 quilômetros de distância do seu núcleo tradicional, contribuem para uma configuração urbano-territorial em que seus limites já não são mais definidos, causados pela disseminação dos valores urbanos referentes à cidade de Dublin em um amplo território de influência e abrangência (Williams \& Shiels, 2002; Hall \& Pain, 2006).
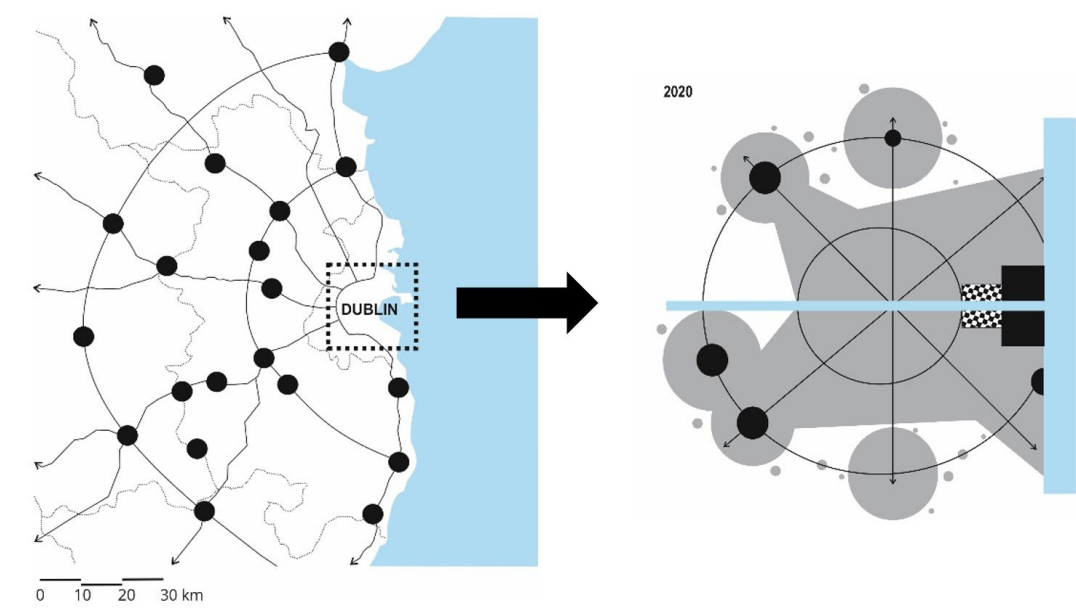

Figura 12 - Diagrama correlacionando a forma urbana de Dublin com a atividade portuária em 2019. Em cinza: mancha urbana; preto: atividades portuárias e industriais; azul: rio Liffey (linha horizontal) e mar da Irlanda (mancha vertical); quadriculado em preto e branco: porção central obsoleta; linha preta: eixos de conexão; linha pontilhada: limites político-administrativos. Fonte: Elaborado pelo autor com base nas imagens de satélite Google Earth (Google, 2019). 


\section{Forma urbana e a atividade portuária: correlações na organização do território de Dublin}

Ao compreender como ocorreu o processo de expansão da mancha urbana de Dublin e as transformações no sistema portuário desde sua gênese até a cidade contemporânea, relaciona-se como essas variáveis interferiram na organização territorial ao longo do tempo. Entre sua origem, no século XII, até o início do século XIX, a forma urbana de Dublin manteve-se compacta, com seus limites claramente definidos. A atividade portuária estava atrelada à porção urbana central, e gradativamente sua expansão direcionou-se ao mar. Por sua vez, os eixos de conexão do porto com o território irlandês foram as estruturas que ordenaram o crescimento urbano da capital irlandesa, em sentido oposto ao porto. Posteriormente, a partir da metade do século XIX e ao longo do século XX, a facilidade de locomoção pelo território potencializou novos assentamentos descontínuos à mancha urbana e desvinculados funcionalmente do centro tradicional. A acessibilidade aos novos modais de transporte por grande parte da população e a flexibilidade nas relações trabalhista e no processo produtivo facilitaram a expansão extensiva da cidade de Dublin e acarretaram a interiorização das estruturas portuárias e industriais, $a$ priori, nas bordas da cidade e, em seguida, pelos núcleos circunvizinhos a Dublin.

A lógica da implantação dos empreendimentos industriais e daqueles relacionados à atividade portuária não se firmava unicamente pela implementação de um modelo de cidade dispersa e/ou policêntrica. 0 cerne desta proposta de descentralização encontrava-se em um plano econômico de âmbito nacional de reequilíbrio econômico dentro do conjunto de cidades irlandesas. Entretanto, a presença das estruturas viárias de origem no centro tradicional de Dublin em sentido ao interior do país aliado à monocentralidade histórica da capital potencializaram a formação de uma rede urbanoregional/nacional vinculadas à cidade de Dublin, como ponto central, e a sua desconcentração industrial e portuária.

A superação gradativa da distância territorial mediante as contínuas e sucessivas ondas de inovação tecnológica permitiu a transformação da cidade industrial para uma cidade informacional (Castells, 1989). Neste sentido, pode-se observar que a condição ordenadora das grandes estruturas de conexão ganha uma nova escala e sentido, à medida que confere suporte material aos fenômenos de dispersão e difusão urbana no território (Monclús \& Dematteis, 1998; Indovina, 2009). Fenômenos esses que marcam o processo contemporâneo de organização do território e redefinem o papel de "centralidade" exercido pelas cidades.

Diante de diferentes estágios de aproximação e principalmente afastamento entre a atividade portuária e a cidade tradicional, enquanto forma urbana, esse processo instaurou, primeiramente, a fragmentação do tecido de borda da mancha urbana e subsequentemente a dispersão, devido à escala territorial que essas novas ocupações urbano-portuários conduziram na mancha urbana de Dublin. Em paralelo à desconcentração das atividades produtivas, intensificaram-se o esvaziamento e a obsolescência da área urbano-portuária central. Não tardou para que um projeto de readequação do centro tradicional promovesse a transformação da cidade industrial para a cidade informacional, e a constituição de novas centralidades interconectadas pelo território, que atinge na contemporaneidade escalas cada vez mais distantes e longínquas.

\section{Conclusão}

A dissociação porto-cidade, frequentemente presente na literatura, deve ser ponderada diante da escala territorial que algumas cidades assumem, entre elas, Dublin. Em se falando somente da cidade que se origina pelo porto tradicional, a qual acaba se tornando o centro tradicional da metrópole portuária, há o afastamento físico, funcional, logístico, econômico e até cultural entre ambos. Em se considerando a escala do território, onde a cidade-região se espraia e se formaliza a metrópole portuária, a dissociação é bem mais tênue. Ao serem agregados às unidades portuárias outros equipamentos urbanos e outras funções urbanas diversas, é possível que se estabeleçam novas centralidades e, com elas, outra 
configuração urbano-territorial. Contudo, é certo que as estruturas que dão suporte ao sistema portuário possuem, atualmente, um caráter mais logístico do que de fomento ao desenvolvimento local.

O que se nota é que a atividade portuária tem efeitos não só sobre o quadro econômico, mas também sobre o território envolvido, sendo capaz de modificá-lo significativamente ao longo do tempo, alterando a forma urbana existente e corroborando na formação de uma nova organização territorial. Essas dinâmicas criam centralidades, dispersões e obsolescências. Por sua vez, a matriz geográfica e os fatores histórico-culturais locais potencializam tais dinâmicas com menores ou maiores amplitudes, e se revelam como condicionantes que engendram as formas das cidades.

A rigor, e como demonstrado pelos modelos expostos, o porto, lugar de trocas de mercadorias, porta de entrada e saída para as pessoas e até mesmo para intercâmbios culturais e, inicialmente, propulsor do desenvolvimento local, transforma-se em um equipamento com foco industrial e logístico, atuando como um nó dentro de uma rede regional/mundial. A obsolescência das antigas estruturas portuárias perante esse novo cenário levou ao seu gradual desuso e/ou sua reconversão para novas atividades desvinculadas à sua função e à sua forma original. Deste modo, na contemporaneidade, intensifica-se uma nova relação território-funcional entre os portos e suas cidades genitoras, cuja relação de proximidade e cooperação original se desfaz progressivamente.

\section{Referências}

Abercrombie, P. (1943). Town and country planning (2nd ed., Vol. 1). London: Oxford University Press.

Adams, J. (1970). Residential structure of midwestern cities. Annals of the Association of American Geographers, 60(1), 37-62. http://dx.doi.org/10.1111/j.1467-8306.1970.tb00703.x.

Arellano, A. F. (2007). Dispersão e difusão na região metropolitana de Barcelona. In N. Portas, N. G. Reis \& M. S. Tanaka (Eds.), Dispersão urbana: diálogo sobre pesquisas Brasil-Europa (Vol. 1, pp. 61-74). São Paulo: FAPESPCNPQ.

Beloto, G. E. (2015). Da região à metrópole: o território desenhado pelos modelos conceituais (Tese de doutorado). Universidade de São Paulo, São Paulo.

Beloto, G. E. (2019). Regional cities: international references in Brazilian regional planning in the 1950s and 1960s. Planning Perspectives, 35(3), 457-476. http://dx.doi.org/10.1080/02665433.2019.1597759.

Bertz, S. (2002). The peripheralisation of office development in the Dublin metropolitan area- the interrelationship between planning and development interests. Irish Geography, 35(2), 197-212.

http://dx.doi.org/10.1080/00750770209555805.

Bird, J. (1963). The major seaports of United Kingdom (Vol. 1). Londres: Hutchison.

Boubacha, E. (1997). Ciudad y puerto: mutación y recomposición. Le Havre: Association Internationale Villes et Ports (AIVP).

Burkle, N. T. (1972). Dublin 1600-1800: a study in urban morphogenesis (Tese de doutorado). Trinity College Dublin, Dublin.

Castells, M. (1989). The informational city: economic restructuring and urban development (Vol. 1). Cambridge: Basil Blackwell.

Conzen, M. R. G. (2004). Thinking about urban form: papers on urban morphology, 1932-1998. Bern: Peter Lang.

Corboz, A. (2004). El territorio como palimpsesto. In A. Ramos (Ed.), Lo urbano em 20 autores contemporáneos (Vol. 1, pp. 25-34). Barcelona: UPC.

Corrêa, R. L. (2003). Região e organização espacial (7th ed., Vol. 1). São Paulo: Editora Ática.

Costa, N. M. S. M. (2007). Mobilidade e transporte em áreas urbanas. $O$ caso da área metropolitana de Lisboa (Tese de doutorado). Universidade de Lisboa, Lisboa. 
Ducruet, C. (2004). Les villes-ports laboratoires de la mondialisation (Tese de doutorado). Université du Havre, Havre.

Garreau, J. (1991). Edge city: life on the new frontier (Vol. 1). Nova Iorque: Doubleday.

Google (2019). Mapa de Dublin, Irlanda, em Google Earth. Recuperado em 20 de setembro de 2019, de https://earth.google.com/web/.

Hall, P., \& Pain, K. (2006). The polycentric metropolis: learning from mega-city regions in Europe (Vol. 1). Londres: Earthscan.

Hayuth, Y. (1982). The port-urban interface: an area in transition. Area, 14(3), 219-224. Recuperado em 20 de setembro de 2019, de www.jstor.org/stable/20001825

Hein, C. (2011). Port cities: dynamic landscapes and global networks (Vol. 1). Nova Iorque: Routledge.

Horner, A. A. (1979). Change in the urban hinterland: a long-term perspective for Dublin. Irish Geography, 12(1), 82-91. http://dx.doi.org/10.1080/00750777909555745.

Howard, E. (1902). Garden cities of tomorrow. Londres: S. Sonnenschein.

Hoyle, B. S. (1989). The port-city interface: trends, problems and examples. Geoforum, 20(4), 429-435.

http://dx.doi.org/10.1016/0016-7185(89)90026-2.

Indovina, F. (2009). Dalla città difusa all'arcipelago metropolitano (Vol. 1). Milão: Franco Angeli.

MacLaran, A. (1993). Dublin: the shaping of a capital. London: Belhaven.

MacLaran, A., \& Punch, M. (2004). Tallaght: the planning and development of an Irish New Town. Journal of Irish Urban Studies, 3(1), 17-39. Recuperado em 20 de setembro de 2019, de http://hdl.handle.net/2262/67680

Meyer, H. (1999). City and Port: transformation of port cities - London, Barcelona, New York, Rotterdam. Rotterdam: International Books.

Monclús, F. J., \& Dematteis, G. (1998). La ciudad dispersa: suburbanización y nuevas periferias (Vol. 1). Barcelona: Centre de Culture Contemporánea de Barcelona.

Moore-Cherry, N., \& Vinci, I. (2012). Urban regeneration and economic crisis: past development and future challenges in Dublin, Ireland. Planum - Journal of Urbanism, 25(2), 1-16. Recuperado em 20 de setembro de 2019, de http://hdl.handle.net/10197/4355

Notteboom, T. E., \& Rodrigue, J. P. (2005). Port regionalization: towards a new phase in port development. Maritime Policy \& Management, 32(3), 297-313. http://dx.doi.org/10.1080/03088830500139885.

Panerai, P. (2006). Análise urbana (Vol. 1). Brasília: EdUnB.

Purdom, C. B. (1949). The building of satellite towns: a contribution to the study of town development and regional planning (2nd ed., Vol. 1). London: J M Dent \& Sons.

Redmond, D., Crossa, V., Moore, N. \& Williams, B. (2007). Dublin as an emergent global gateway: pathways to creative and knowledge-based regions. Amsterdã: AMIDSt.

Reis, N. G. (2006). Notas sobre urbanização dispersa e novas formas de tecido urbano. São Paulo: Via das Artes.

Solà-Morales i Rubió, M. (1997). Las formas de crecimiento urbano (Vol. 1). Barcelona: UPC.

Tourinho, A. 0. (2007). Do centro às novas centralidades: uma trajetória de permanências terminológicas e rupturas conceituais. In M. L. C. Gitahy \& J. T. C. Lira (Orgs.), Cidade: impasses e perspectivas (Vol. 2, Arquiteses, pp. 11-28). São Paulo: Annablume Editora.

Van den Berg, L., et al (1982). Urban Europe: a study of growth and decline. Oxford: Pergamon.

Vasconcelos, F. N. (2011). O desenvolvimento da interface cidade-porto em Vitória (ES) do período colonial ao início do século XXI: uma cidade portuária? (Tese de doutorado). Pontifícia Universidade Católica de São Paulo, São Paulo. 
Williams, B., \& Shiels, P. (2002). The expansion of Dublin and the policy implications of dispersal. Journal of Irish Urban Studies, 1(1), 1-20. Recuperado em 20 de setembro de 2019, de http://hdl.handle.net/2262/68480

Zaremba, P. (1962). Les príncipes du développement des villes portuaires. Académie Polonaise des Sciences, 32(1), 1-33.

Editor: Rodrigo Firmino

Recebido: Set. 20, 2019

Aprovado: Jul. 03, 2020 